\title{
RECEPCION TELEVISIVA DESDE LA FAMILIA: una propuesta Sistémica para su Estudio
}

\author{
Luis Alfonso Guadarrama Rico \\ Centro de Investigación y Estudios Avanzados en Ciencias Politicas y \\ Administración Pública. UAEM
}

\section{Introducción}

La televisión como objeto de estudio ha presentado variaciones tanto en su concepción como en las metodologías que de ella se han derivado. Los últimos años de la década de los sesentas y durante los setentas, disciplinas como la sociología, la antropología, el psicoanálisis, la lingüística y la ciencia política, proporcionaron un bagaje teórico muy diverso, gracias al cual la investigación se fue diversificando en enfoques y perspectivas.

Este aparato tecnológico, tan común, y en la mayoría de los casos imprescindible, forma parte del inventario de lo que una familia o individuo posee; basta tener en cuenta el uso masificado que ha tenido en los distintos grupos sociales ${ }^{1} \mathrm{y}$, aunque inicialmente se consideró que el principal objetivo era informar y educar al espectador así como entretenerlo, al ir en busca de este fin, se han configurado una serie de fenómenos distintos que han cuestionado la función, los efectos y los procesos que genera. En tal sentido, hay quienes plantean que la televisión genera consumismo, desunión familiar, pasividad, violencia, o, que instaura y mantiene formas de comportamiento diversas. (Guerro, 1986)

Una de las imágenes que más se propagó acerca de la televisión y su impacto en la población infantil, consistió en ilustrar un cuadro en el que un niño (a), frente al televisor, estaba dominado por la pasividad; una clara 1 Hace apenas poco más de medio siglo que en Alemania se inauguró la primera emisora de televisión. En 1939, cuatro años después de su inicio, I los Estados Unidos de Norteamérica, a través de la National Broadcasting Company (NBC) ponían en marcha sus transmisiones y, dos años más tarde, en ese país se autorizaba la explotación comercial publicitaria de los diversos canales establecidos. En México, hacia finales de 1946 se inauguró la primera estación de televisión, aunque la mayoría coincide en señalar al año de 1950 como el antecedente oficial de la televisión en México. 
interpretación conductista -frecuentemente referida en los textos de comunicación como teoría de la "aguja hipodérmica"- pues se pensó que el televidente se encontraba condicionado por los estímulos que emitía la televisión. Sin embargo, este enfoque fue sacudido por planteamientos como los de Wilbur Schramm, al referir que el niño no era una entidad pasiva, sujeto a la acción del aparato, sino un agente activo capaz de seleccionar de la televisión los mensajes más adecuados a sus necesidades e intereses, derivando como corolario que la influencia de la televisión era diferente y única en cada infante (Schramm, 1982).

En nuestro país, hacia finales de la década de los sesentas el fenómeno de la televisión empezó a ser objeto de investigación. Fuentes Navarro anota que en 1968 se publicó la primera investigación sobre el tema; fue una tesis presentada en la Universidad Iberoamericana (UIA), intitulada "La televisión y el alumno de secundaria del Distrito Federal, cuyo autor fue Raúl Cremoux. ${ }^{2}$ A partir de entonces la televisión ha llamado la atención de varios tesistas e investiga- dores acerca de este medio masivo. De hecho, como lo afirma Enrique Sánchez Ruíz, la televisión -junto con la radio- han sido los medios que más se han investigado en nuestro país (Sánchez Ruiz, 1986).

Pese a lo que algunos suponen, el debate es aún acalorado. Como se verá más adelante, a pesar de los numerosos estudios sobre la televisión y la diversidad de enfoques con los que se ha investigado, los resultados, -en ángulos específicos del fenómeno-, resultan contrapuestos y, en otros, han llamado la atención sobre nuevos factores que, amalgamados a ese comportamiento tan común como es el "ver televisión", ayudan a dar cuenta de procesos antes insospechados o no atribuidos a la relación con este medio masivo. Demos una sucinta mirada a la serie de investigaciones que se han conformado a lo largo del tiempo, apoyadas en marcos teóricos venidos, esencialmente, de las disciplinas sociales.

\section{Roles Sexuales y Televisión}

El contenido de los programas transmite y recrea a través de la participación de personajes, los roles socialmente correspondiente a uno y otro género. Se afirma que los niños no sólo diferencian los roles sexuales sino que, además, aprenden e interiorizan patrones de conducta y de actitudes del sexo con el

2 Citado por Fuentes Navarro, Raúl. "La investigación mexicana en comunicación. sistematización documental 1956-1986” en: Sánchez Ruíz, Enrique. LA INVESTIGACION DE LA COMUNICACION EN MEXICO: Logros, Retos y Perspectivas. ED. Universidad de Guadalajara y Ediciones de Comunicación S.A. de CV., México, 1986. 
que se identifican. Esta línea de trabajo, como lo anotan Rota y Fernández, busca sustentar por qué las telenovelas muestran más preferencia por parte de las niñas o de las mujeres adultas dedicadas al hogar, mientras que los programas de acción y deportivos tienen mayor auditorio masculino. ${ }^{3}$ Puede suponerse que ante determinado programa televisivo los niños perciben selectivamente actitudes, valores, y conceptos que reflejan los personajes masculinos y las mujeres parecen dar preferencia al rol de los personajes femeninos. Sin embargo, es necesario detenerse un poco para llamar la atención sobre los que indica Mauricio Guerrero "la televisión no es la única ni la principal influencia sobre las actitudes y valores de los infantes... (Pues) cuando la televisión presenta valores y modelos de comportamiento que no son consecuentes con los valores que los padres presentan a sus hijos, no hay razón para creer que la influencia de la televisión sea fundamental" (Guerrero, 1986:64).

\section{Televisión y Violencia}

Uno de los binomios más recurrentes en esta temática se relaciona con el impacto de la televisión en la conducta agresiva. Un estudio reportado por Eron afirma que hay una relación positiva entre violencia televisada y agresión en los niños. De la programación infantil, se estimó que un niño promedio percibía unas quince escenas violentas por cada hora de transmisión.

Realizados los cálculos, Eron estimó que un pequeño que permanece tres horas diarias mirando televisión, llevaría a un total de 315 escenas violentas por semana. Esta condición, plantea que la población infantil está cada día más familiarizada con la violencia. No obstante, quizá este es uno de los aspectos sobre los que más controversia existe, pues investigadores como Freedman postulan que no hay sólidas evidencias para apoyar tal noción, dado que las investigaciones realizadas presentan serios problemas de orden metodológico y, consecuentemente, impiden una generalización de este tipo. ${ }^{4} \mathrm{~A}$ este respecto, Wilbur Schramm ofrece argumentos para alimentar aún más la controversia, al sostener que en realidad "el mayor número de índice agresivo mostrado por los hombres deviene del carácter originado por las interacciones sociales y la cultura en general, en contraposición con lo que sucede en

3 Rota y Fernández, citados por López Cunningham, Ana Cristina. LA TELEVISIÓN Y SU INFLUENCIA EN NÑOS (TESINA), UNAM, Facultad de Psicología, México, 1989.

4 Ambos autores citados por López Cunningham, Op. cit 
las mujeres, quienes no suelen imitar la violencia televisiva (...) Es como si la socialización femenina construyera un escudo protector contra la penetración de los modelos agresivos incluso de los protagonizados por mujeres" (Schramm, 1982: 128).

\section{Televisión y Consumismo}

En este aspecto parecen coincidir la mayoría de los investigadores. Sostienen que la televisión, a través de los anuncios, estimula el consumismo en la sociedad. Particularmente, aunque no exclusivamente, los niños parecen ser los receptores más vulnerables a la influencias de los anuncios. Un estudio realizado por Anaya y otros, encontraron sensibles cambios en el régimen alimentario, después de la aparición de la televisión en varias comunidades rurales de la República Mexicana (Anaya, et. al., 1984).

En suma, podemos mencionar que en los albores de la investigación acerca de este tema, dominó el paradigma conductista o un modelo de efectos. Se conceptualizó a la televisión, más preciso, ver televisión, como una variable independiente y a los comportamientos observados en los receptores como variable dependiente del contenido programático. La idea que se tenía del receptor era de un elemento pasivo al que le beneficiaba o perjudicaba la exposición con los programas televisivos. Después se fue descentrando a la televisión para tratar de dar cuenta de las condiciones del receptor, contribuyendo con ello a destacar su actividad, tanto manifiesta como no observable.

\section{Televisión y Familia}

Trabajos recientes han puesto en claro que la tele- visión se encuentra inscrita en la vida doméstica y en las rutinas familiares y que por lo tanto "ver televisión" exige cierta compatibilidad con los ritmos de actividad de sus miembros y quizá constituye el eje de gravitación de los intercambios personales.

Las costumbres de la familia y las relaciones que se gestan y suceden al interior de esta unidad básica, parecen prefigurar los hábitos televisivos. Autores como Furó, mencionan que el papel que desempeñan los padres de familia y los hermanos mayores, abren o cierran el abanico de temas pro gramático s a los que puede tener acceso un infante, ${ }^{5}$ es decir, Furó identifica como una variable importante del consumo pro- gramático el papel que desempeñan los miembros mayores de la familia, respecto a los menores.

5 Citado por López Cunningham, Op. cit 
James Lull, quien sigue una perspectiva basada en reglas, estudió los procedimientos de selección y los patrones de comunicación familiar, y concluyó que las familias emplean la televisión para evitar comunicarse o conversar a cierta profundidad sobre aspectos particulares, cuestión que hace pensar en este medio masivo como un regulador de la comunicación entre los miembros de las familias. ${ }^{6}$

Sin embargo, Goodman -quien trabaja desde una perspectiva sistémicaseñala que cuando la televisión constituye un medio empleado frecuentemente para evitar o interrumpir la comunicación en la familia, ha de interpretarse como un síntoma de desequilibrio en el sistema familiar global y no como una conducta social aislada, dado que "ver televisión" y la comunicación interpersonal, forman parte de una dinámica interaccional, incrustada en la cotidianidad de la propia familia (Goodman, 1983). Cuando este autor señala "desequilibrio en el sistema familiar", a mi parecer, ofrece una pista muy interesante acerca de la recepción televisiva y esta unidad de análisis que es la familia, pues en tanto sistema, la integran elementos (en este caso individuos) que desempeñan funciones distintas, roles, rutinas y generan un clima o dinámica interaccional que podría prefigurar las formas y matices en los que se desarrollan los momentos de “ver televisión”. Este planteamiento será desarrollado con detenimiento, más adelante.

Ubicado en la misma perspectiva Lulliana, Leoncio Barrios desarrolló un estudio etnográfico, con el propósito de analizar la relación entre la televisión y la comunicación en el contexto de la familia. Parte de sus resultados apuntan que "los problemas de comunicación familiar suelen ser multicausados por factores tanto intra como extrafamiliares” (Barrios, 1992:71)

Por su parte, Morley, aunque no emplea una perspectiva estrictamente etnográfica para acercarse a la recepción, nos presenta un análisis de las prácticas de expectación genéricamente determinadas y de las dinámicas familiares, a través de las cuales ofrece una interpretación del contexto familiar y cómo éste debe ser empleado para buscar entender las formas de ver televisión (Morley, 1986). Dentro de este mismo interés, Orar encuentra que en los matrimonios de estructura patriarcal, los hombres suelen sentarse a ver su programa favorito de televisión, mientras que las mujeres no pueden hacerlo, por una parte, porque los miembros masculinos toman precedencia

6 Ver: Lull, James. "The social uses of televisión” en: HUMAN COMUNICATION RESEARCH. Vo16, No. 3, 1980. También, ver del mismo autor: World Families Watch Television, Sage, Newbury Park, C.A, 1988 y, INSIDE FAMIL y VIEWING. ETHNOGRAPHIC RESEARCH ON TELEVISION'S AUDIENCIES. de. Routledge, ION DON AND NEW YORK, 1990. 
y, por otra, porque la atención de las mujeres se divide entre la pantalla y las peticiones de los esposos e hijos (Gray, 1987).

Basada en la categoría de las multimediaciones, Martha Renero, pone en el centro de su atención a la madre de familia como "el agente social de más peso en el ámbito doméstico y por ende, la interacción madre-hijos es el proceso más influyente en la recepción televisiva de estos últimos" (Renero, 1992:33). El interés de la autora fue analizar cómo la mediación materna es capaz de crear, re-crear y articular diferentes prácticas de comunicación encaminadas a la super- vivencia cultural de la institución familiar y cómo esta mediación ayuda a explicar las apropiaciones y aprendizajes que los niños derivan de su interrelación con la programación televisiva.

En un reporte de investigación Nora Segura Escobar analiza los resultados de un estudio de campo en el que aplicó cuestionarios a 152 hogares, aunque el respondiente de estos instrumentos fue únicamente la mujer dedicada al hogar, como la autora señala, considera que "la centralidad de la mujer en el hogar la convertía en la televidente más propensa a lo largo del día y probablemente la persona mejor informada sobre los hábitos y rutinas de otros miembros" (Segura, 1992: 180). Asimismo, señala que "Las formas de consumo televisivo y las relaciones conflictivas o no con otras actividades y hábitos de la familia, dependen, entre otros factores, del grado de diferenciación del espacio habitacional, de la relación entre número de televisores disponibles y número de miembros de la familia, y del grado de incompatibilidad entre actividades y personas" (Segura, 1992:188).

Como se puede notar, la mayoría de los estudios referidos en el último apartado, han privilegiado tanto las formas de interacción, como los papeles o roles que algunos miembros de la familia dejan ver o connotan en el proceso de recepción, sin embargo, parece haber un gran ausente en una buena parte de las investigaciones encontradas hasta ahora: la familia. Poco se ha dicho sobre las características de la familia; de esa unidad básica o de ese grupo social en el que ocurre la recepción televisiva, y sí -en cambio- se perfilan rutinas, formas de consumo, centralidad de la madre; interacción madre-hijos; consumo de programas según géneros, etc. Pero ¿de qué tipo de familias se habla? Desde luego, se dan indicadores acerca del nivel socioeconómico; de la urbanidad o ruralidad de las familias, o bien se habla de grados de permisividad vigente en los padres, pero ¿la estructura de la familia? ¿la dinámica que le constituye y da cuerpo ? ¿La edad de los padres y por lo tanto la generación de familia de la que se habla? ¿El número de miembros que originalmente componían a la familia y que en el momento de la investigación la componen más o menos? ¿Las ocupaciones de cada miembro de la familia? ¿Su edad y, 
en buena medida, el marco de sus intereses? No aparecen en los reportes de investigación. Se da por sentado que es suficiente con decir que se trata de una familia urbana o rural, de nivel socioeconómico alto, medio o bajo, independientemente de su estructura y dinámica. Como indica Andrée Michel, "no puede hablarse teóricamente de la familia en general sino únicamente de tipos de familia..."(Michel, 1974:7).

En otras palabras, si bien se sabe que la actividad de ver televisión es un proceso gobernado por reglas, la tarea obliga a tratar de explicitar esas reglas que emergen de estructuras particulares de familias y buscar comprender cómo operan en este fenómeno que resumidamente se ha etiquetado como "ver televisión".

¿Cómo construir y dar cuenta de estos cimientos y pisos del edificio, para después arribar, nuevamente, a la centralidad de la recepción televisiva en y desde la familia? Considero que una posibilidad puede ser construida utilizando el aparato conceptual sistémico. En el campo de la psicología, varios autores $^{7}$ precisamente desde la perspectiva sistémica, han estudiado los procesos de organización y modalidades de relación interpersonal, estableciendo como punto de partida la clarificación de la estructura y tipología de la familia de la que se trata.

\section{Televisión y familia, una propuesta sistémica}

De acuerdo con Cusinato, un sistema se puede definir como cualquier entidad abstracta o concreta, constituida por partes interdependientes. Los organismos vivos se conceptúan como sistemas abiertos, debido a que intercambian materia con el ambiente que les rodea. Así, el estado normal de un organismo vivo o sistema abierto no es el equilibrio. Debido a ello, dentro de la concepción sistémica se presta atención al comportamiento interactivo y a los procesos de autorregulación y transformación del sistema familiar como conjunto compuesto por individuos (Cusinato, 1992:228-237).

En términos formales y apoyados en Giddens, la familia puede ser definida como "un grupo de personas directamente ligadas por nexos de parentesco, cuyos miembros adultos asumen la responsabilidad del cuidado de los hijos" (Giddens, 1991:415). Los lazos de parentesco constituyen nexos entre individuos, establecidos vía el matrimonio o la unión libre que ligan genealógicamente a los consanguíneos (madres, padres, descendientes, tíos, abuelos, etc.). Para los propósitos de este trabajo, tal definición sería insuficiente.

7 Por ejemplo, Grinker, 1967; Miller, 1978; Bateson, 1976 y Munuchin, 1994. 
La familia, vista desde el enfoque sistémico, es un sistema abierto; entidad dinámica que está en proceso de cambio continuo, lo mismo que sus contextos sociales, es decir, recibe y envía, desde su interior des- cargas al medio extrafamiliar o, si se quiere, recibe presión del exterior originada en los naturales requerimientos que le demanda el contexto socio-histórico para acomodarse a las instituciones sociales significativas que influyen sobre los miembros familiares. Al mismo tiempo, está sometida a presión interna originada por la evolución de sus propios miembros y subsistemas. Por ello, este grupo relacional primario siempre ha sufrido cambios que guardan cierta correspondencia con las modificaciones que suceden en la sociedad a la que pertenece y de la cual forma parte. Sus funciones, en lo interno, es la protección psicosocial de sus miembros y, en lo externo, como lo marca Minuchin, "la acomodación a una cultura y a la transmisión de esa cultura" (Minuchin, 1994:78).

Esta unidad ha de ser vista como totalidad en tanto compuesta por formas de vida diferentes, donde cada parte cumple su papel, pero, como lo puntualizan Munuchin y Fischsman, "el todo constituye un organismo de múltiples individuos, que en sí mismos son una forma de vida” (Minuchin, 1993:26). Este organismo familiar, procede según reglas preexistentes pero eventualmente pueden suceder cambios que de- mandan transformaciones, debido a que las personas que conforman a la familia, en cada una de sus interacciones, sólo manifiestan parte de sus posibilidades. Estas suelen ser múltiples y acaso insospechadas, pero emergen sólo algunas debido a la posibilitación que ofrece la estructura del contexto. Cuando los contextos sufren modificaciones, es decir, se amplían o surgen quiebres, existen posibilidades de que surjan nuevas interacciones. Las personas se acomodan en forma de caleidoscopio para lograr la reciprocidad que posibilita las relaciones humanas. Por ejemplo, un cambio en la posición jerárquica en el seno de la familia produce un cambio en cada uno de sus miembros y en lo que se considera permitido en las interacciones entre ellos.

En razón de estas características, es indispensable entender que la familia es un sistema social en transformación que presenta muchas fases en su evolución natural a lo largo del tiempo y que en esa dinámica, la familia y por ende sus miembros buscan adaptarse a través de la negociación de nuevas reglas familiares, en las que aparecen nuevos subsistemas y se trazan también nuevas líneas de diferenciación, no sin distintos niveles de conflicto. De esto se desprende que a la familia es necesario conceptualizarla e investigarla como un sistema que posee una estructura en movimiento. 
¿Cómo iniciar la documentación de la familia?

Un elemento que ayuda a trazar un panorama básico de la familia y que permite orientar la generación de preguntas valiosas, en materia de recepción televisiva, es el empleo de lo que en teoría sistémica se denomina genograma. Veamos en qué consiste y cuáles podrían ser las ventajas.

De acuerdo con McGoldrick y Gerson, el genograma es "un formato para dibujar un árbol familiar que registra información sobre los miembros de una familia y sus relaciones..."(McGoldrick y Gerson, 1990: 17). Es decir, constituyen representaciones gráficas de una familia y permiten explorar su estructura y, digamos, "poner al día" el cuadro familiar. Aunque los genogramas en terapia familiar son empleados fundamentalmente para estudiar árboles familiares de por lo menos tres generaciones, ello no impide su aplicación en otras áreas del conocimiento. A través de un genograma podemos tener información gráfica de la estructura de cada una de las familias que pretendemos estudiar en materia de recepción televisiva.

Si bien este recurso, derivado de la teoría de los sistemas familiares de Murray Bowen, está muy generalizado entre los terapeutas y algunos médicos familiares de los Estados Unidos de Norteamérica y de Italia, no parece haber un acuerdo estandarizado acerca de los criterios técnicos que deben seguirse para realizar "correctamente" un genograma. No obstante, un grupo de terapeutas de la Task Force of the North American Primar Care Research, ha propuesto una simbología y algunos procedimientos básicos para realizar el trazado del genograma. Basado en él, pero con algunas adaptaciones necesarias para su aplicación en el ámbito de la recepción televisiva, enseguida describo los elementos constitutivos.

Un genograma supone tres niveles:

1. trazado de la estructura familiar

2. registro de la información sobre la familia y,

3. delineado de las relaciones familiares

\section{Estructura familiar}

Este primer nivel constituye la columna vertebral de un genograma. Representa gráficamente cómo están biológica y legalmente ligados entre sí los miembros de una familia. El trazado está basado en figuras que representan a cada una de las personas y líneas que describen las relaciones entre ellas.

Cada miembro está representado por un cuadrado o un círculo; según su género, para el masculino, cuadrado y para el femenino el círculo. Para una persona fallecida, se coloca una equis dentro de la figura geométrica. Las 
fechas de nacimiento y de fallecimiento se indican a la izquierda y a la derecha, separado por dos puntos entre un año y otro, si no hay motivo de posible confusión respecto del siglo al que pertenece.

Para representar las relaciones biológicas y legales entre los miembros de la familia se usan líneas de diversos tipos. Líneas horizontales, verticales y continuas para marcar a dos personas casadas; el género masculino situado a la izquierda y la mujer a la derecha. Si se considera significativo, puede ser especificado sobre la línea horizontal el año en que se contrajeron nupcias, antecedida de la letra minúscula "m". En la línea de casamiento se pueden indicar variantes como la separación (identificada con una línea inclinada) o el divorcio (con dos líneas inclina- das). Si una pareja tiene una relación, viven juntos o en unión libre, se ilustra su relación con línea segmentada. En este caso también puede resultar de interés especificar el año en el que se conocieron o empezaron a vivir juntos.

Cuando la pareja tiene hijos, la figura geométrica que representa a cada uno pende de la línea que conecta a la pareja. Los hijos trazan de izquierda a derecha, siguiendo el orden de nacimiento. Para casos de pareja con hijos adoptivos, se emplean líneas punteadas. Finalmente, se trazan líneas convergentes para identificar a hijos mellizos y, en caso de que éstos sean idénticos, se agrega una barra que los conecte.

\section{Información familiar}

Una vez trazada la estructura familiar, se procede a agregar información relevante que pueda contribuir a mejorar el entendimiento y exploración de la recepción televisiva, en particular aspectos relacionados las edades de cada uno de los miembros, fechas de nacimiento, muertes, ocupaciones y nivel educacional.

\section{Relaciones familiares}

Este tercer nivel en la construcción de genogramas exige un mayor cuidado, toda vez que se refiere a la relación entre los miembros de una familia. Este tipo de información es recomendable obtenerla a través de entrevistas con algún miembro de la familia o bien, de ser posible, con más de uno, con el propósito de probar la confiabilidad de la información. Los tipos de relación que se pueden representar en el genograma, aunque no exclusivamente, pueden estar clasificados en seis: 
1. Muy unidos o fusionados, para el se emplean tres líneas en paralelo.

2. Fusionados y conflictivos, para el que se usan tres líneas en paralelo y encima líneas "quebradas" o grecas.

3. Pobre o conflictivo, líneas grecas o "quebradas"

4. Unidos, dos líneas en paralelo.

5. Apartados o separados, una línea con un segmento en blanco, acotadas con una o dos líneas perpendiculares, según la condición de la separación (legal o de mutuo acuerdo)

6. Distante, línea punteada.

Trazado el genograma, podemos formular preguntas orientadoras para indagar aspectos específicos acerca de la propia estructura y dinámica que priva en la o las familias de interés y, posteriormente, con este tipo de información, favorecer la comprensión del fenómeno televisivo en y desde la familia, vista como un sistema.

\section{Bibliografía}

Anaya, C.V., et al. EL IMPACTO DE LA TV EN CINCO COMUNIDADES VIRGENES EN MEXICO. Ed. UNAM-UNICEF, México, 1984. Barrios, Leoncio. “Televisión, comunicación y aprendizaje en el contexto de la familia. Estudio etnográfico realizado en Venezuela” en: Orozco, Guillermo (Comp). HABLAN LOS TELEVIDENTES. ESTUDIOS DE RECEPCION EN VARIOS PAISES. Cuadernos de Comunicación y Prácticas Sociales No. 4., Ed. UIA, México, 1992.

Cusinato, Mario. PSICOLOGIA DE LAS RELACIONES FAMILIARES.

Ed. Herder, Barcelona, 1992.

Fuentes Navarro, Raúl. "La investigación mexicana en comunicación. Sistematización documental 1956-1986” en: Sánchez Ruíz, Enrique. LA INVESTIGACION DE LA COMUNICACION EN MEXICO: Lógros, Retos y Perspectivas. Ed. Universidad de Guadalajara y Ediciones de Comunicación S.A. de C.V., México, 1986.

Giddens, Anthony. SOCIOLOGÍA. De. Alianza Universidad, Madrid, 1991. Goodman, Y. “TV's Role in Family Interaction” en: JOURNAL OF F AMIL Y ISSUES. Vol. 4, Núm 2, 1983.

Gray, A. "Behind closed doors: Video recorders in the home" En: H. Baerh \& G. Dyer (eds.), basado en: Women and television. Ed. Pandora, London, 1987. 
Convergencia Revista de Ciencias Sociales, núm. 8/9, 1995, Universidad Autónoma del Estado de México

Guerrero Martínez, Mauricio. UNA APROXIMACION A LA INFLUENCIA PSICOLOGICA DE LA TELEVISION EN LOS NIÑOS. (Tesis), México, 1986.

López Cunningham, Ana Cristina. LA TELEVISION y SU INFLUENCIA

EN NIÑOS (TESINA), UNAM, Facultad de Psicología, México, 1989.

Lull, James. "The social uses of televisión" en: HUMAN COMUNICA-

TION RESEARCH. Vol 6, No. 3, 1980.

Lull, James. World Families Watch Television, Sage, Newbury Park, C.A, 1988. Lull, James. INSIDE FAMILY VIEWING. ETHNOGRAPHIC RESEARCH ON TELEVISION'S AUDIENCIES. Ed. Routledge, IONDON AND NEW YORK, 1990.

McGoldrick, Monica y Randy Gerson. GENOGRAMAS EN LA EVALUACIÓN FAMILIAR. Ed. Gedisa, España, 1990.

Michel, Andrée. SOCIOLOGIA DE LA FAMILIA Y DEL MATRIMONIO. Ed. Península, Barcelona, 1974.

Minuchin, Salvador. FAMILIAS Y TERAPIA FAMILIAR. De. Gedisa, Barcelona, 1994; 78.

Morley, David. FAMILY TELEVISION, CULTURAL POWER AND DOMESTIC TEISURE. Ed. Comedia, Londres, 1986.

Munuchin, $S$ y Fischman, H. Ch. TECNICAS DE TEPARIA FAMILIAR. Ed. Paidós, México, 1993.

Orozco, Guillermo. "Familia, televisión y educación en México. La teoría educativa de la madre como mediación en la recepción televisiva de los niños. En HABLAN LOS TELEVIDENTES. Estudios de recepción en varios países. Cuadernos de Comunicación y Prácticas Sociales, núm. 4, Iberoamericana, México, 1992.

Renero Quintanar, Martha. "La mediación familiar en la construcción de la audiencia. Prácticas de control materno en la recepción "tele-viciva" infantil” en: Orozco, Guillermo (Comp). HABLAN LOS TELEVIDENTES. ESTUDIOS DE RECEPCION EN V ARIOS PAISES. Cuadernos de Comunicación y Prácticas Sociales No. 4., Ed. UIA, México, 1992.

Sánchez Ruíz, Enrique. "La investigación de la comunicación y el análisis social en Latinoamérica y en México” en: Sánchez Ruíz, Enrique. Op.cit.

Schramm, Wilbur, et. al. TELEVISION PARA LOS NIÑOS. Ed. HispanoEuropeo, España, 1982.

Segura Escobar, Nora. "Usos sociales de la televisión y de la telenovela. La Familia frente a la televisión: Hábitos y rutinas de consumo en Cali” en: Martín-Barbero, Jesús y Sonia Muñoz. TELEVISION Y MELODRAMA. Ed. Tercer Mundo Editores, Colombia, 1992. 